\title{
Índice de vegetação por diferença normalizada associado às variáveis pluviométricas para a sub-bacia do Rio Espinharas - PB/RN
}

\author{
Ewerton Medeiros SIMÕES ${ }^{1}$, Joedla Rodrigues de LIMA ${ }^{1 *}$, \\ Izaque Francisco Candeia de MENDONÇA ${ }^{1}$ \\ ${ }^{1}$ Centro de Saúde e Tecnologia Rural, Universidade Federal de Campina Grande, Patos, PB, Brasil. \\ *E-mail: joedlalima@yahoo.com.br \\ (Orcid: 0000-0003-0786-543X; 0000-0001-6617-2858; 000-0002-3445-4532)
}

\begin{abstract}
Recebido em 20/05/2020; Aceito em 03/02/2021; Publicado em 26/02/2021.
RESUMO: No semiárido brasileiro, onde se insere o bioma caatinga, a precipitaçãos é um dos fator limitante para seu desenvolvimento sócioeconômico e ambiental, este estudo avaliou a correlação existente entre o nível de cobertura vegetal e as variáveis pluviométricas locais, considerando a climatologia de 2005 e 2015, utilizandose imagens dos sensores TM e OLI dos satélites Landsat 5 e Landsat 8, respectivamente. O ano de 2005 apresentou maiores valores de NDVI em relação a 2015, com valores máximos de 0,71 e 0,78 no período seco e úmido, respectivamente. No ano de 2015, os valores máximos são de 0,64 e 0,61, para o período seco e úmido, respectivamente. Os maiores valores foram observados no período chuvoso de 2005, nas áreas de influência das estações meteorológicas de Matureia, Salgadinho e Areia de Baraúnas. No período seco, nota-se a baixa variabilidade dos valores de NDVI, sendo as maiores leituras observadas nas estações de Matureia, Salgadinho e Teixeira. As estações que apresentaram as maiores reduções nos valores de NDVI de 2005 para 2015, no período chuvoso, foram Matureia, Santa Teresinha e Salgadinho, com reduções de 41,9\%, 38,2\% e $32,7 \%$, respectivamente. As correlações mais significativas foram estabelecidas para os períodos secos. As menores correlações foram verificadas no período chuvoso. A elevação dos níveis pluviométricos na região não implicou o aumento progressivo nos valores de NDVI.
\end{abstract}

Palavras-chave: semiárido; geoprocessamento; índice de vegetação normalizada.

\section{Normalized difference vegetation index associated with pluviometric variables for Espinharas River sub-basin - PB/RN States}

\begin{abstract}
In the Brazilian semiarid, where the caatinga biome is inserted, precipitation is a limiting factor for its socioeconomic and environmental development, This study evaluated the correlation between the level of vegetation cover and the local rainfall variables, considering the climatology of 2005 and 2015, using images from the TM and OLI sensors of the Landsat 5 and Landsat 8 satellites, respectively. The year 2005 presented higher NDVI values compared to 2015, with maximum values of 0.71 and 0.78 in the dry and wet periods, respectively. In 2015, the maximum values are 0.64 and 0.61 , for the dry and wet periods, respectively. The highest values were observed in the rainy period of 2005, in the weather stations of Matureia, Salgadinho and Areia de Baraúnas. In the dry period, the low variability of NDVI values is noted, with the highest readings observed in the Matureia, Salgadinho and Teixeira platforms. The platforms that showed the greatest reductions in NDVI values from 2005 to 2015, in the rainy season, were Matureia, Santa Teresinha and Salgadinho, with reductions of $41.9 \%, 38.2 \%$ and $32.7 \%$, respectively. The most significant correlations were established for the dry periods. The smallest correlations were found in the rainy season. The increase in rainfall levels in the region did not imply a progressive increase in NDVI values.
\end{abstract}

Keywords: semiarid; geoprocessing; normalized difference vegetation index.

\section{INTRODUÇÃO}

A caracterização climatológica do semiárido nordestino é representada, em série histórica, por precipitações médias inferiores a $800 \mathrm{~mm}$, temperaturas médias entre $23^{\circ}$ e $27^{\circ} \mathrm{C}$, evaporação de $2.000 \mathrm{~mm}$, baixos índices de umidade relativa do ar, com média anual de aproximadamente 50\%. A hidrografia da região, de regime intermitente, apresenta processos avançados de assoreamento face às adversidades intrínsecas de sua fisiografia. A pedologia é representada predominantemente por unidades de solos com fortes limites restritivos de seus atributos, destacam-se Luvissolos Crômicos e Neossolos Litólicos, configurando condições adversas para o desenvolvimento de sua vegetal natural e, sobretudo, à exploração agrícola com fins econômicos. A vegetação xerófita componente de um sistema ambiental fortemente fragilizado, historicamente, foi impactada pela exploração extensiva de seus solos, representada pelas pecuárias bovina e caprina, associando-se o uso agrícola sem o devido ordenamento espacial. Estas condições sugerem, dentre outras aplicações científicas, a execução de estudos que revelem as interações entre o componente espaço/tempo representado pela dinâmica da cobertura vegetal e pela precipitação, o que tem sido possível pelo emprego de ferramentas computacionais que auxiliam no 
monitoramento integrado sistema ambiental. A utilização de sensores remotos orbitais, em séries temporais, vem se destacando na comunidade científica por proporcionar uma avaliação sinóptica, rápida e precisa do meio ambiente (FOODY, 2010; NASSUR et al., 2015; XIAOLIN; DESHEND, 2014).

Dentre as diversas técnicas empregadas para o monitoramento e avaliação das mudanças na estrutura, fisionomia e dinâmica na cobertura florestal, no decorrer do tempo, destaca-se o Índice de Vegetação por Diferença Normalizada (NDVI) (AQUINO; OLIVEIRA, 2012). O NDVI, como instrumento para o monitoramento da vegetação, apresenta alta sensibilidade à densidade da cobertura vegetal, tornando possíveis comparações espaciais e temporais da atividade fotossintética, assim como o monitoramento sazonal, interanual e mudanças em longo prazo dos parâmetros biofísicos, fenológicos e estruturais da vegetação (PONZONI; SHIMABUKURO, 2010).

Considerando a expressiva importância de pesquisas nesta temática, que contribui para o desenvolvimento sustentável, notadamente este trabalho através do estudo da sub-bacia hidrográfica do Rio Espinharas, localizada na região semiárida dos estados da Paraíba e Rio Grande do Norte. Nesta região se insere o município mais populoso do semiárido, com demandas por alimento e energia justificando a relevância desta pesquisa.

De acordo com Silva et al. (2014), esta sub-bacia apresentou, no ano de 2010, 66\% de sua área ocupada por atividades antrópicas, fato que merece atenção dos órgãos e gestores, visto que essa ocupação de forma desordenada, expõe os solos a processo de degradação com alto grau de severidade, limitando à regeneração da fitomassa, derivando restrições na qualidade e disponibilidade hídrica da sub-bacia.

O objetivo deste estudo foi avaliar a correlação existente entre o nível de cobertura vegetal $\mathrm{e}$ as variáveis pluviométricas locais, considerando a climatologia de 2005 e 2015, utilizando-se imagens dos sensores TM e OLI dos satélites Landsat 5 e Landsat 8 respectivamente.

\section{MATERIAL E MÉTODOS}

O estudo foi conduzido na sub-bacia hidrográfica do Rio Espinharas, que integra a bacia hidrográfica do Piranhas-Açu, considerado um dos mais importantes sistemas hídricos da Região Semiárida nordestina.A metodologia está organizada na seguinte sequência: delimitação da área, a delimitação da sub-bacia hidrográfica do Rio Espinharas, $\mathrm{PB} / \mathrm{RN}$, após a seleção das imagens a serem utilizadas, realizou-se o cálculo do NDVI, distribuindo-se em classes, segundo EMBRAPA (1979), com apoio de trabalho de campo para reambulação dos dados e aplicação da correlação com o uso do Indice de correlação de Pearson (R).

A sub-bacia do Rio Espinharas é formada pela confluência do Rio da Cruz e o Rio Farinhas. O Rio da Cruz nasce no município Imaculada-PB, segue no sentido nordeste em direção ao município de Patos - PB. O Rio Farinhas nasce na Serra do Aba, contraforte do planalto da Borborema. Sua principal nascente é o Riacho do Ferro, também conhecido como riacho Acauã localizado no município de Salgadinho - PB (ARAUJO et al., 2011). A partir de sua nascente, o Rio Farinhas segue uma distância de aproximadamente $70 \mathrm{Km}$, no sentido oeste confluindo com o Rio da Cruz, no município de Patos, PB, formando o Rio Espinharas. A partir daí o Rio segue no sentido sudoeste/nordeste até o município de Serra Negra do Norte,
RN, integrando-se ao Rio Piranhas-Açu.

A área de estudo é de aproximadamente $3.289,79 \mathrm{Km}^{2}$, localizada nos estados da Paraíba e do Rio Grande do Norte, circunscrita nos limites dos paralelos: $6^{\circ} 25^{\prime} 50.9$ S" e $7^{\circ} 21^{\prime}$ 48.6 S" e pelos meridianos $37^{\circ} 33^{\prime} 09,7$ W' e $36^{\circ} 43^{\prime} 52,3$ W" (Figura 1).

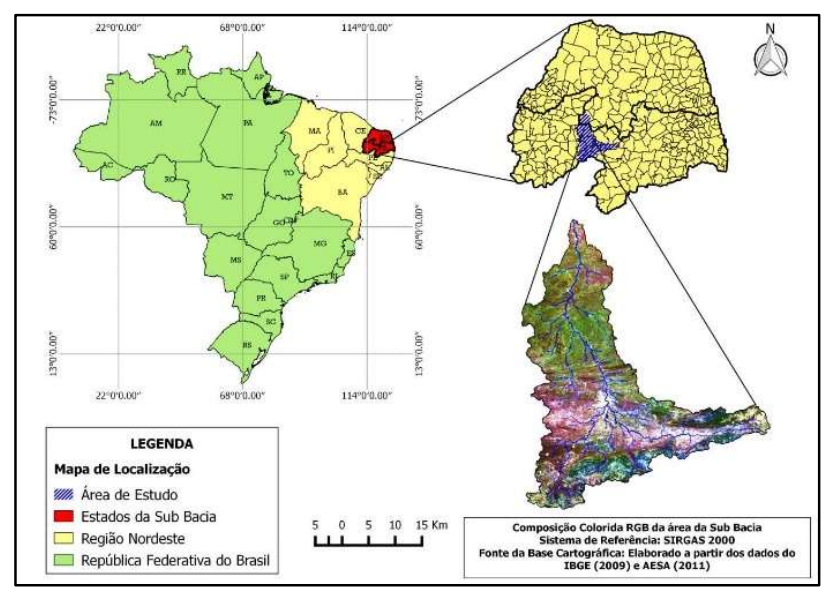

Figura 1. Localização geográfica da Sub-bacia Hidrográfica do Rio Espinharas.

Figure 1. Geographic location of the Espinharas River Hydrographic Sub-basin.

A área está inserta nos limites do bioma Caatinga e de clima semiárido, com precipitações distribuídas de maneira irregular no espaço/tempo com solos rasos, pedregosos, cristalinos e susceptíveis à erosão (SILVA; LIMA; MENDONÇA, 2014).

Segundo a classificação de Koppen, o clima da porção sudeste da sub-bacia é classificado como Bsh - quente e seco, com ocorrência de chuvas de verão, média pluviométrica de, aproximadamente, $500 \mathrm{~mm}$ anuais e temperatura média anual em torno de $26^{\circ} \mathrm{C}$ e Aw'. Na porção centro-ocidental da área de estudo, o clima é quente e semiúmido, com presença de chuvas de verão-outono, média pluviométrica anual em torno de $800 \mathrm{~mm}$ e temperatura média anual de $27^{\circ} \mathrm{C}$ (AESA, 2010).

A delimitação dos divisores topográficos foi realizada através de um Modelo Digital de Elevação (MDE) proveniente de imagens SRTM (Shuttle Radar Topography Mission), obtidas junto ao Serviço Geológico dos Estados Unidos (USGS), disponíveis no endereço "earthexplorer.usgs.gov" (SOBRINHO et al., 2010).

A delimitação da área da sub-bacia foi realizada com o emprego do SIG Quantum GIS versão 2.8.5, através da extensão TauDEM-Terrain Analysis Using Digital Elevation Model. Foram confeccionados, através de técnicas de geoprocessamento, os mapas hipsômetros e de declividade do terreno. Para o estudo das variações do NDVI, nos anos de 2005 e 2015, com imagens de sensoriamento remoto, foi construído um banco de dados geográfico no software IDRISI Andes ${ }^{\circledR}$.

Foram utilizadas imagens multiespectrais dos satélites LANDSAT 5-TM e LANDSAT 8 OLI, disponibilizadas pelo site da NASA (www.earthexplorer.com) da órbita 215 e ponto 65. Para o estudo temporal do comportamento do NDVI, em dois períodos distintos (seco e chuvoso), foram utilizadas as bandas 3 (vermelho) e 4 (infravermelho próximo) do sensor TM e bandas 4 (vermelho) e 5 (infravermelho próximo) do sensor OLI/TIRS, especificadas na Tabela 1. 
Tabela 1. Identificação das imagens orbitais com cobertura para a área de estudo.

Table 1. Identification of orbital images with coverage for the study area.

\begin{tabular}{cccc}
\hline Satélite & Sensor & Órbita/ponto & Data \\
\hline Landsat 5 & TM & $215 / 065$ & $07 / 03 / 2005$ \\
Landsat 5 & TM & $215 / 065$ & $02 / 11 / 2005$ \\
Landsat 8 & OLI & $215 / 065$ & $06 / 05 / 2015$ \\
Landsat 8 & OLI & $215 / 065$ & $29 / 10 / 2015$ \\
\hline
\end{tabular}

Foram selecionadas imagens de satélite que apresentaram menor percentual de cobertura de nuvens, para os períodos seco e chuvoso dos anos de 2005 e 2015 . O intervalo decenal estabelece uma melhor avaliação da dinâmica da fitomassa da vegetação da caatinga, através do contraste entre a vegetação e solo.

O processamento das imagens foi realizado utilizando o programa IDRISI Andes versão 15.0, licenciado pelo Laboratório de Geoprocessamento da Universidade Federal de Campina Grande UFCG. As imagens foram reprojetadas para o sistema de projeção Universal Transversa de Mercator (UTM), Datum horizontal Sirgas 2000 - Zona 24 S. Foi utilizado o método polinomial de $1^{\circ}$ grau, utilizando como referência uma imagem ortorretificada do Landsat $5 \mathrm{da}$ região, com utilização de, aproximadamente, 20 pontos de controle (PCs), com base em pontos de amarração confiáveis e reconhecíveis nas duas imagens, tais como interseções entre estradas, caminhos, rios e etc. Os pontos de controle foram coletados com Erros Médios Quadráticos (RMS) inferiores a 0,5 pixel. O método de reamostragem dos valores de brilho foi a do vizinho mais próximo.

Foi realizada a correção radiométrica das imagens, a fim de corrigir eventuais erros de transmissão dos dados e influências atmosféricas. Esse processo possibilita a conversão dos números digitais da imagem em valores de radiância $(L \lambda)$, representando a radiação solar refletida por cada pixel que compõe a imagem. O cálculo da radiância foi obtido pela equação proposta por Markham e Barker (1987) (Equação 1).

$$
L \lambda \mathrm{i}=\left[\operatorname{Lmin}+\frac{\operatorname{Lmax}-\operatorname{Lmin}}{255}\right] \times 255
$$

em que: $\mathrm{L} \lambda \mathrm{i}=$ radiância espectral de cada banda (Calibração radiométrica); $L \min , \mathrm{Lmax}=$ são as radiâncias espectrais mínimas $\mathrm{e}$ máximas; $\mathrm{ND}=$ é a intensidade do pixel (número digital - número inteiro de 0 a 255); i = são as bandas $(1,2,3,4,5,6$ e 7) do satélite Landsat 5 sensor TM.

Para o cálculo do NDVI, foi realizada a subtração de imagens para avaliar a dinâmica da cobertura vegetal dos anos estudados. Assim, o NDVI pode ser definido pela expressão matemática da razão entre a diferença da reflectância das bandas do infravermelho próximo e vermelho, pela soma dessas mesmas bandas (equação 2) (ROUSE et al., 1974).

$$
\mathrm{NDVI}=\frac{\mathrm{P} 4-\mathrm{P} 3}{\mathrm{P} 4+\mathrm{P}}
$$

em que: P4 = Infravermelho próximo; $P 3$ = Vermelho

O NDVI foi dividido em classes, criando-se uma categoria temática com o objetivo de facilitar a visualização da modificação ou variação dos valores do NDVI. Para cada classe criada foi atribuída uma cor.

Foi gerada uma malha de pontos correspondente à localização geográfica de doze estações de coleta de dados (PCD), situadas nos municípios de Areia de Baraúnas, Mãe d' Água, Matureia, Passagem, Patos, Quixaba, Salgadinho, Santa Teresinha, São José do Bonfim, São José do Espinharas, Serra Negra e Teixeira. A partir de cada PCD, foi determinado um raio de $5 \mathrm{~km}$, no qual foram marcados aleatoriamente 30 pontos amostrais para aquisição dos valores de NDVI em áreas de vegetação natural (Figura 2).

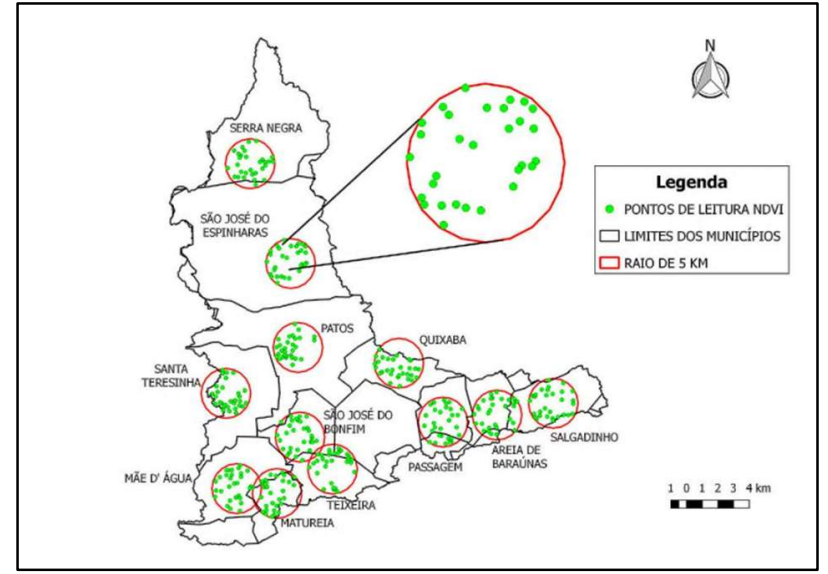

Figura 2. Localização espacial dos pontos de leitura de NDVI. Figure 2. Spatial location of NDVI reading points.

Os valores obtidos pelo NDVI resultaram no estabelecimento das classes de vegetação da área a ser estudada. O índice foi determinado para os anos de 2005 e 2015, nos períodos seco e chuvoso, tornando possível identificar possíveis mudanças ocorridas na cobertura vegetal no período determinado.

Para o cálculo do NDVI, foi realizada a subtração de imagens para avaliar a dinâmica da cobertura vegetal dos anos estudados. $\mathrm{O}$ aumento da vegetação verde é diretamente proporcional à reflexão do infravermelho próximo e inversamente proporcional na banda do vermelho.

As leituras dos valores do NDVI foram realizadas em cada ponto amostral, dentre os 12 municípios avaliados, em cada uma das 4 imagens. A escolha desses municípios foi baseada na localização de cada estação pluviométrica, somente os municípios com suas estações dentro dos limites da área de estudo foram selecionados, com exceção da plataforma de Cacimba de Areia, que apresentou falhas nas leituras pluviométricas no ano de 2015. Os valores de NDVI foram organizados em planilha eletrônica.

Para a escolha dos pontos a serem visitados em campo, utilizou-se o programa Google Earth PRO 6.2, do qual foram selecionadas as áreas de interesse. As coordenadas dos pontos foram transferidas para o aparelho GPS para orientar na localização dos pontos no terreno. Após a localização dos alvos terrestres, eles foram registrados com uma câmera digital, com resolução de 12 megapixels.

Os dados de precipitação referentes ao acumulado em 2005 e 2015, até a data de passagem das imagens dos períodos seco e chuvoso, foram obtidos junto à Agência Executiva de Gestão das Águas do Estado da Paraíba (AESA) e Empresa de Pesquisa Agropecuária do Rio Grande do Norte (EMPARN).

Foi analisada a distribuição pluviométrica média anual de cada município, assim como sua distribuição espaçotemporal na área de estudo. Para isto, foram utilizados os dados de precipitação média anual de cada plataforma de 
coleta de dados (PCD), disponibilizados pela AESA e EMPARN.

Os dados médios de NDVI, obtidos para os meses secos e chuvosos, foram correlacionados com a precipitação acumulada no período até a data imagem. Em seguida, foram realizados testes estatísticos de correlação, com a intenção de verificar a provável relação entre a precipitação e as leituras de NDVI, com enfoque no comportamento da vegetação com a distribuição irregular das chuvas no espaço-tempo. A correlação entre essas variáveis foi realizada através do índice de correlação de Pearson (R).

\section{RESULTADOS}

A rede hidrográfica da sub-bacia do rio Espinharas se estende, completa ou parcialmente, por vinte e dois municípios, situando-se nas mesorregiões do Sertão Paraibano e Borborema, envolvendo partes das microrregiões de Patos, Sousa, Serra de Teixeira, Seridó Ocidental e Cariri Ocidental, no estado da Paraíba (AESA, 2010). No estado do Rio Grande do Norte, está situada em parte da mesorregião Central Potiguar e na microrregião do Seridó Ocidental (IBGE, 2010). Possui cursos d'água de regime de escoamento intermitente, com padrão de drenagem predominantemente dendrítico (SILVA et al., 2011).

O Rio Espinharas está inserido na Depressão Sertaneja Setentrional, formado por uma extensa planície pediplanada, com altitudes que variam de 131,2 a 1185,9 m de altitude, compostas por elevações residuais, os inselbergues, que são difusamente distribuídos ao longo da paisagem (Figura 3).

Foram encontradas seis classes de declividades para a área de estudo, com base nas normas estabelecidas pela Embrapa (1979) (Figura 4). A área possui uma extensa superfície classificada como plano $574,09 \mathrm{~km}^{2}$ (16,77\%), suave ondulada $1575,49 \mathrm{~km}^{2}$ (46,02\%), ondulada 701,21 $\mathrm{km}^{2}$ $(20,48 \%)$, forte ondulada $463,7254 \mathrm{~km}^{2}(13,54 \%)$ e, de forma isolada, planícies Montanhosas 101,1276 km² (2,95\%) e Forte montanhosas $7,15 \mathrm{~km}^{2} \quad(0,21 \%)$, representadas pelos Inselbergues.

A partir dos dados disponibilizados pelas estações pluviométricas, gerou-se mapas com a distribuição espacial da média da precipitação para os meses janeiro a dezembro de 2005 e de 2015 (Figuras 6 e 7).

A precipitação acumulada para o ano de 2005 foi semelhante ao ano de 2015, com chuvas concentradas no primeiro semestre, com baixo nível de precipitação para o segundo semestre (Figura 5).

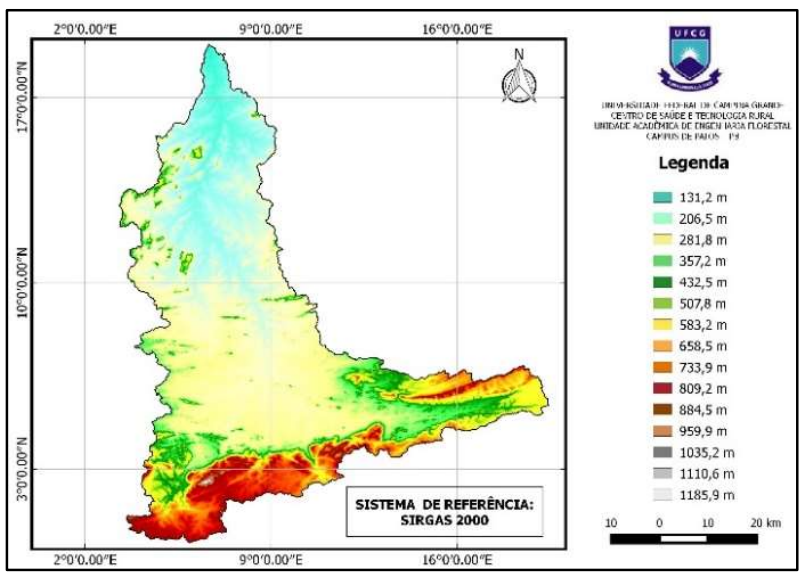

Figura 3. Hipsometria da Sub-bacia do Rio Espinharas.

Figure 3. Hypsometry of the Espinharas River Sub-basin.

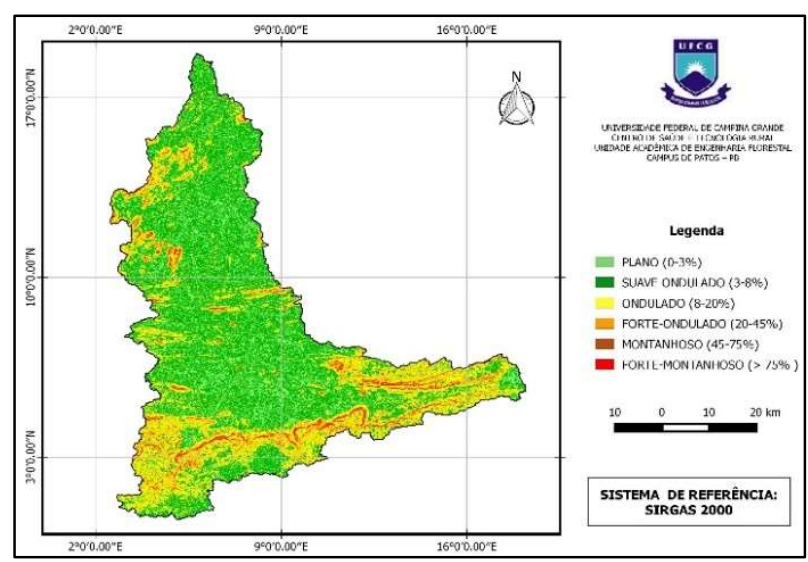

Figura 4. Mapa de declividade da área de estudo. Figure 4. Slope map of the study área.

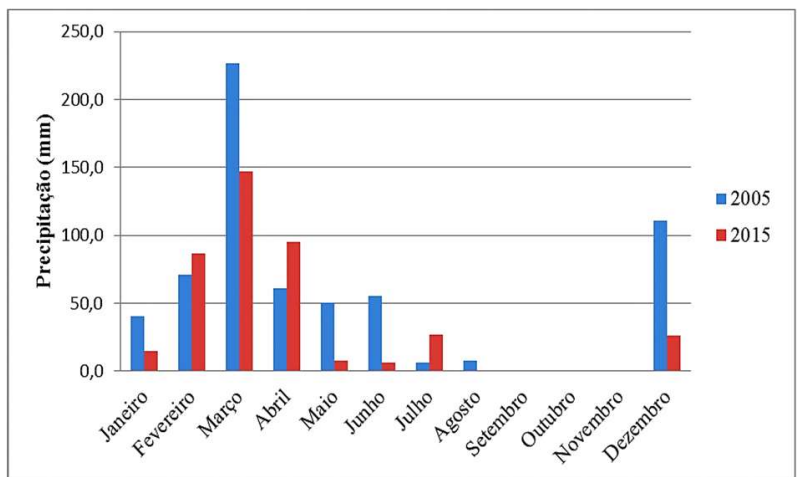

Figura 5. Precipitação acumulada da sub-bacia do Rio Espinharas, nos anos de 2005 e 2015.

Figure 5. Accumulated rainfall in the Espinharas River sub-basin, in the years 2005 and 2015

Os resultados obtidos com a aplicação da equação do NDVI para a sub-bacia do Rio Espinharas foram relacionados aos níveis de reflectância da imagem. Para facilitar a visualização e análises, foi gerada uma composição colorida "falsa cor" para as cenas.

A comparação entre os valores de NDVI, adquiridos com o emprego de imagens orbitais dos meses de julho e novembro de 2005, e imagens de maio e outubro de 2015, estão distribuídos espacialmente nos mapas contidos nas Figuras 8 e 9 .

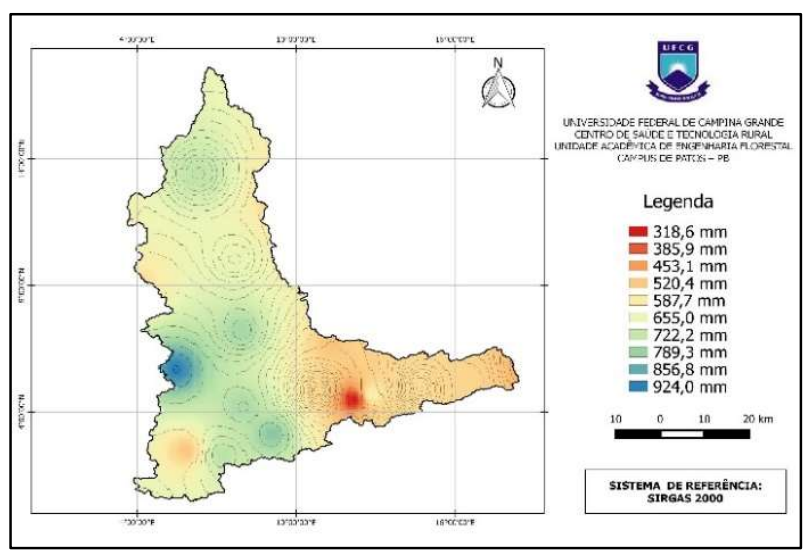

Figura 6. Mapa de precipitação média anual para o ano de 2005 da Sub-bacia Hidrográfica do Rio Espinharas, PB/RN.

Figure 6. Average annual precipitation map for the year 2005 for the Rio Espinharas Hydrographic Sub-basin, PB / RN. 


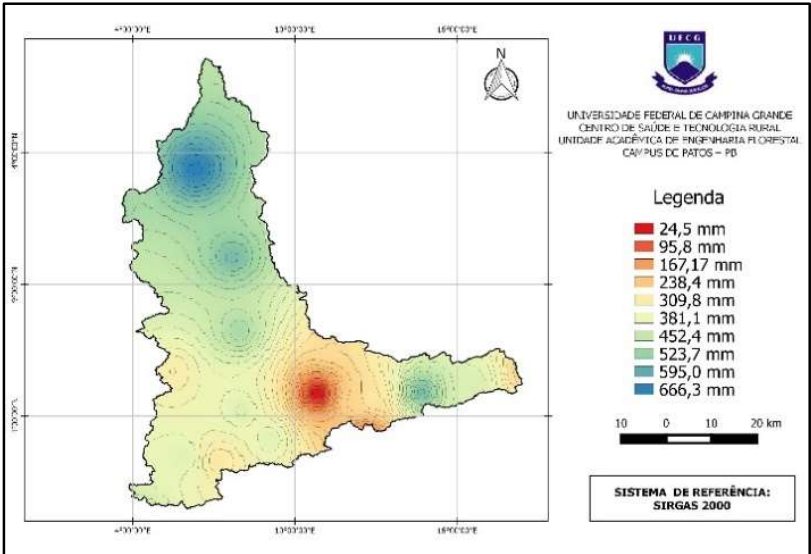

Figura 7. Mapa de precipitação média anual para o ano de 2015 da Sub-bacia Hidrográfica do Rio Espinharas, PB/RN.

Figure 7. Mean annual precipitation map for the year 2015 for the Rio Espinharas Hydrographic Sub-basin, PB / RN.

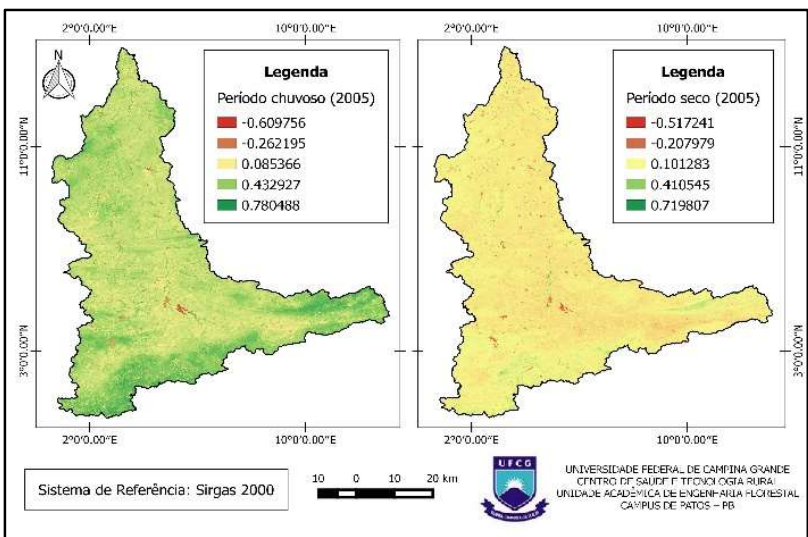

Figura 8. Índice de Vegetação por Diferença Normalizada NDVI, da Sub-bacia do Rio Espinharas, para os períodos chuvoso e seco de 2005.

Figure 8. NDVI Normalized Difference Vegetation Index, of the Espinharas River Sub-basin, for the rainy and dry periods of 2005

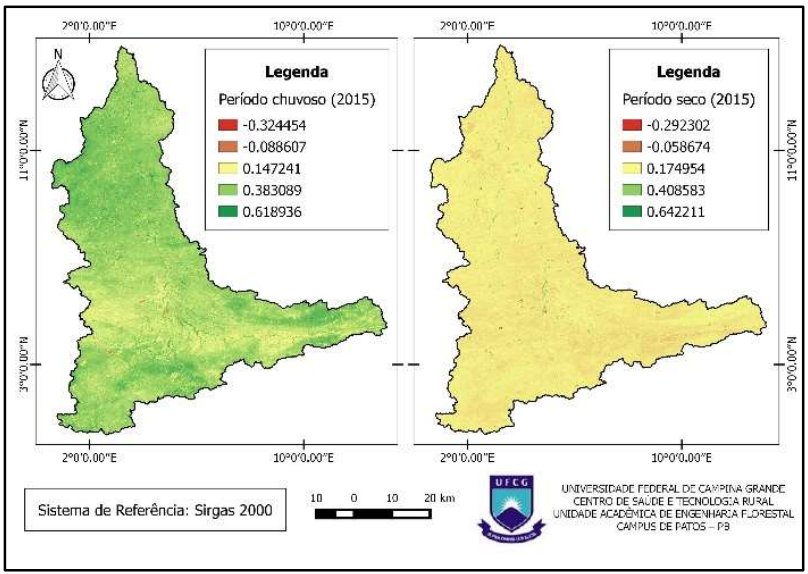

Figura 9. Índice de Vegetação por Diferença Normalizada NDVI, da Sub-bacia do Rio Espinharas, para os períodos chuvoso e seco de 2005.

Figure 9. NDVI Normalized Difference Vegetation Index, of the Espinharas River Sub-basin, for the rainy and dry periods of 2005

Considerando a variação do NDVI na área de estudo, durante os períodos analisados, observam-se mudanças significativas na concentração da vegetação caatinga do período chuvoso para o período seco. No ano de 2005 foram observados valores máximos de reflectância, para os períodos seco e úmido, de 0,71 e 0,78, respectivamente. No ano de 2015, os valores máximos foram de 0,64 e 0,61, para os períodos seco e úmido, respectivamente.

A Figura 10, apresenta o resultado dos valores médios do NDVI por estação meteorológica. O gráfico ressalta uma diferença em relação ao comportamento deste índice, visto que as médias variam bastante de uma plataforma para outra, principalmente no período chuvoso. De maneira geral, podese observar que os maiores valores foram observados no período chuvoso de 2005, nas estações meteorológicas de Maturéia, Salgadinho e Areia de Baraúnas.

Em relação ao período seco, nota-se a baixa variabilidade dos valores de NDVI, sendo as maiores leituras observadas nas estações de Matureia, Salgadinho e Teixeira, nos anos estudados.

Em relação as mudanças ocorridas na cobertura vegetação, nos anos analisados, infere-se que os valores do período chuvoso apresentaram maior variabilidade. Nesse cenário, verifica-se que alguns municípios apresentaram maiores alterações nos valores de um ano para outro, implicando, na prática, incremento ou redução da fitomassa. Os maiores incrementos entre os anos estudados foram verificados nas estações de São José do Espinharas (19,7\%) e São José do Bonfim (12,9\%).

As estações que apresentaram as maiores reduções nos valores de NDVI de um ano para outro, no período chuvoso, foram Matureia, Santa Teresinha e Salgadinho, com reduções de $41,9 \%, 38,2 \%$ e $32,7 \%$, respectivamente.

Para explicar a variação deste índice durante o ano, procedeu-se uma análise de correlação entre os valores de NDVI e a precipitação acumulada. Os diagramas de dispersão foram calculados para cada período, com valores de NDVI no eixo x e os da precipitação no eixo y (Figura 11).

Os resultados exibidos, até então, confirmam as diferenças entre os valores do NDVI nos períodos selecionados, entretanto, há uma maior relação entre o NDVI e a precipitação dos períodos secos, do que em relação aos períodos chuvosos (Figuras11 C e 11-D).

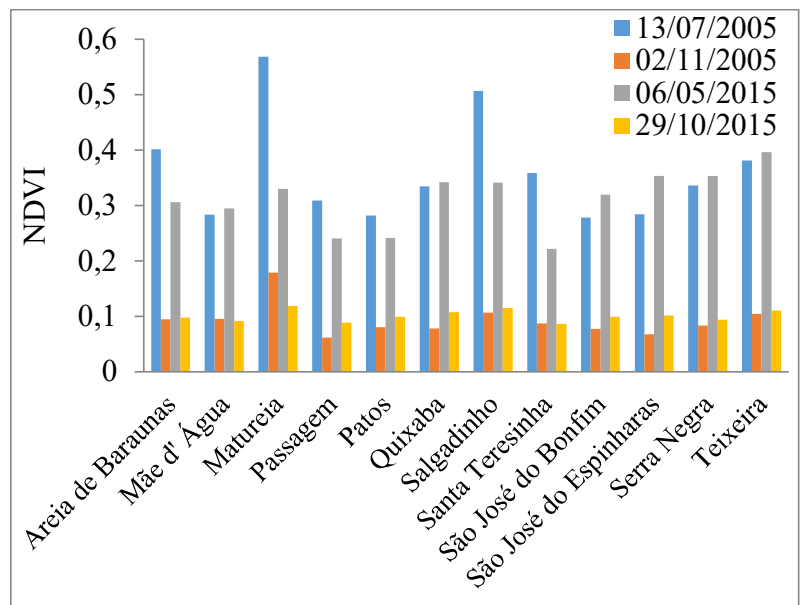

Figura 10. Valores médios de NDVI para as áreas dos municípios que compõem a sub-bacia do Rio Espinharas. As barras em azul e vermelho correspondem a valores de NDVI dos períodos chuvoso e seco de 2005, respectivamente. As barras em verde e roxo correspondem ao período chuvoso e seco de 2015.

Figure 10. Mean NDVI values for the areas of the s that make up the Espinharas River sub-basin municipalities. The blue and red bars correspond to NDVI values for the rainy and dry periods of 2005, respectively. The green and purple bars correspond to the 2015 dry and rainy season. 


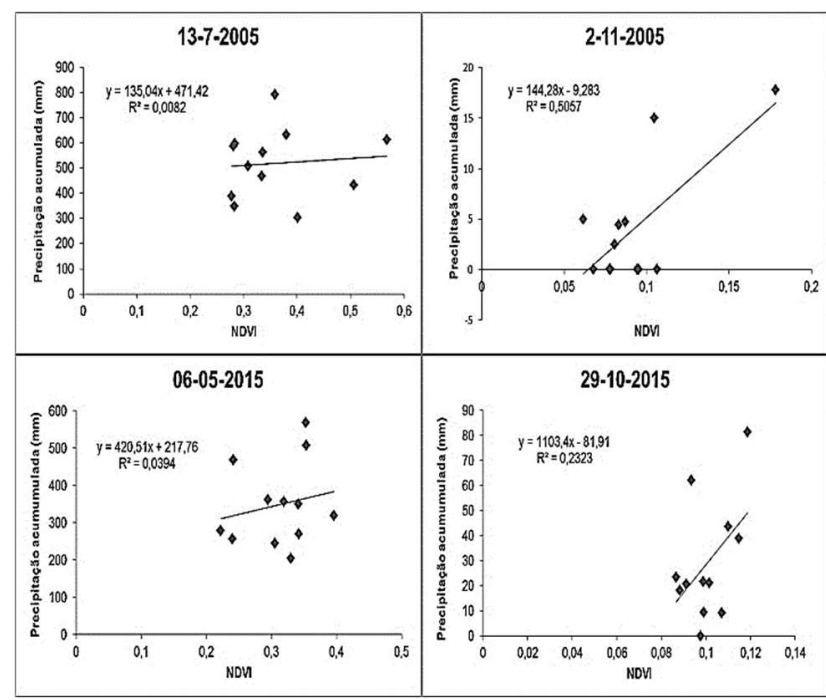

Figura 11. Gráfico de dispersão de NDVI sobre a Sub-bacia do Rio Espinharas, no período chuvoso de 2005 (A) e 2015 (B), e seco de 2005 (C) e 2015 (D), de acordo com a precipitação acumulada em cada ano até a data da coleta de dados.

Figure11. NDVI dispersion graph over the Espinharas River Subbasin, in the rainy period of 2005 (A), and 2015 (B), and dry of 2005 (C) and 2015 (D), according to the accumulated rainfall in each year to date of data collection.

As correlações mais significativas para as variáveis analisadas foram estabelecidas para os períodos secos, com coeficientes de correlação de Pearson de 0,71, em 2005 e 0,48 , para 2015 , indicando uma relação progressiva entre as variáveis com a diminuição dos totais pluviométricos. As menores correlações foram verificadas no período chuvoso, com valores de 0,09, em 2005 e 0,19, para o ano de 2015 .

Uma avaliação da relação entre o NDVI e a chuva mostrou bons coeficientes de correlação para o período seco, com maior valor encontrado para o ano de $2005(\mathrm{R}=0,71)$. Resultado semelhante foi verificado no ano de 2015 ( $\mathrm{R}=$ $0,48)$.

\section{DISCUSSÃO}

De acordo com o mapa hipsométrico apresentado, é possível verificar que as áreas de maiores elevações estão localizadas na parte superior do Planalto da Borborema, porção Sudoeste, localizado no Pico do Jabre, município de Matureia-PB. Em contrapartida, as áreas de menores elevações estão situadas nos terrenos de transição entre o Planalto da Borborema e da Chapada do Apodi, localizada no município de Serra Negra-RN, com altitudes variando entre 130 e $200 \mathrm{~m}$.

A área de estudo é formada predominantemente por uma superfície que varia de suave-ondulado a ondulado $66,5 \%$ do total da área. As áreas com declividades mais acentuadas estão situadas nos municípios de Salgadinho, Areia de Baraúnas e Passagem (Porção Sudeste), e também nos municípios de Teixeira, Matureia e Mae d'Água (porção SulSudoeste)

A declividade do terreno é uma variável importante para a avaliação das terras, pois determina os níveis de estabilidade dos seus componentes físico/químicos e biodinâmicos, servindo também como referência para separar ambientes (FRANCISCO et al., 2012).

Através da análise em torno da distribuição da precipitação ao longo dos anos estudados, verifica-se que o período chuvoso na região se inicia no mês de janeiro e estende-se até meados de maio, com máximas pluviométricas registradas no mês de março. Esse fenômeno geralmente está associado a influência da Zona de Convergência Intertropical (ZCIT).

Quanto ao caráter vegetativo, o mês de julho, neste estudo, pode ser considerado representativo da estação chuvosa na região, devido à precipitação acumulada nos meses anteriores. A partir do mês de julho, devido à caducifólia, as plantas da caatinga sofrem diversas modificações morfológicas e fisiológicas em sua estrutura, que permitem sobreviverem à escassez hídrica na região.

Para tanto, os meses de outubro e novembro são os meses com menores índices pluviométricos, caracterizando bem o período seco na região.

Em relação a distribuição espacial das chuvas ao longo da área de estudo, verificou-se, de maneira geral, uma distribuição irregular das chuvas, com valores inferiores concentrados na porção leste da área, municípios de Areia de Baraúnas, Passagem, Cacimbas, Cacimba de Areia e Salgadinho. Vale salientar que o posto pluviométrico de Cacimba de Areia apresentou em 2015, precipitação inferior a $25 \mathrm{~mm}$, que de acordo com os funcionários da AESA, tratase de uma falha ocorrida no equipamento de coleta dos dados.

De maneira geral, as maiores concentrações pluviométricas foram registradas nos municípios de Santa Teresinha, Teixeira, Patos e Serra Negra, respectivamente.

Através da representação vetorial dos valores de NDVI, conforme visualizado nas figuras 8 e 9 , é possível verificar as alterações ocorrentes no contexto da área de estudo. As áreas com degradê verde são indicativas de vegetação com maior atividade fotossintética, representando os maiores valores deste índice.

Essa vegetação mais vigorosa ocorre nas margens dos cursos de água, devido à maior disponibilidade hídrica anual, e nas áreas de maiores declividades topográficas. A conservação e a intensificação da cobertura vegetal nas áreas mais declivosas do terreno são reflexo do menor impacto causado pela pressão antrópica ao ambiente, por serem geralmente áreas remotas e difícil acesso (CUNHA et al., 2012).

A intensidade de vegetação presente em cada pixel da imagem é representada pelos valores positivos de NDVI. No entanto, solos expostos, rochas e áreas urbanas (construções e asfalto) refletem na banda do vermelho $(0,63 \mu \mathrm{m}-0,69 \mu \mathrm{m})$ e no infravermelho próximo $(0,76 \mu \mathrm{m}-0,90 \mu \mathrm{m})$, basicamente na mesma intensidade, e isso explica os valores próximos de zero desses alvos (CUNHA et al., 2012).

Os valores negativos de NDVI (cores vermelho e marrom) representam os corpos de água, sombras e nuvens na imagem. Esses alvos refletem de forma mais intensa na banda do vermelho do que na banda do infravermelho próximo, por isso possuem valores negativos.

Os menores valores positivos de NDVI entre os períodos analisados foram representados pela coloração amarela no mapa, indicando vegetação de baixa atividade fotossintética, com valores situados entre 0,08 e 0,14 , para o período chuvoso, e 0,10 e 0,17, para o período seco. Da Silva Barbosa et al. (2017), obtiveram, na região serrana de Martins e Portalegre-RN, valores alternando entre negativos e positivos $(-0,04-0,03)$ para áreas com presença de baixa atividade fotossintética, com alvos de superfície sem vegetação e cobertura vegetal menos densa. Na região semiárida do Rio Grande do Norte, Bezerra et al. (2013) encontraram valores 
na ordem de 0 a 0,2 para áreas com solo exposto e vegetação caducifólia rala. Valores de NDVI menores que 0,4 , para o período seco, são mais compatíveis para respostas da vegetação de Caatinga hiperxerófila (LOPES et al., 2010).

Através da análise comparativa entre os períodos seco e chuvoso é possível observar, a expressividade dinâmica do bioma caatinga. Conforme observado nas figuras 8 e 9 , em geral, os valores do NDVI são mais elevados no período chuvoso, indicando uma maior atividade fotossintética da vegetação. Outrossim, no período de escassez hídrica, esses valores são reduzidos, ampliando a área com baixa atividade fotossintética, seja pela ausência de folhagem (dossel decíduo) e/ou presença de solos expostos.

Os valores positivos correspondem à presença de uma vegetação mais vigorosa, com regeneração do dossel no período chuvoso, em face de boa disponibilidade de água no perfil do solo, proporcionando condições próprias ao equilíbrio biológico da vegetação.

A deciduidade e o desenvolvimento de novas folhas da vegetação caatinga é fortemente influenciada pela quantidade de chuva na região. Essas espécies aclimam-se à seca liberando suas folhas no período de escassez hídrica, com o intuito de reduzir a perda de água para a atmosfera por transpiração (LIMA; RODAL, 2010). No período chuvoso, ocorre renovação das copas das árvores, e consequentemente aumento dos valores de NDVI, devido à elevação da atividade fotossintética (FERREIRA et al., 2012). O NDVI possui alta correlação com a quantidade clorofila encontrada na vegetação (PONZONI; SHIMABUKURO, 2010).

No período referente a 2015 , os valores máximos de NDVI foram verificados no período seco, contrariando os dados apresentados no ano de 2005. Vale ressaltar que tal aumento, deve-se a presença de áreas formadas por culturas irrigadas, bosques de Prosopis juliflora e vegetação ciliar, localizadas, principalmente, ao longo dos cursos de água como barragens e açudes.

Segundo Bezerra (2013), os valores de NDVI acima de 0,4 , no período de estiagem, são referentes à mata ciliar situada às margens dos rios, aproveitando a água disponível para prover suas necessidades fisiológicas, e às culturas irrigadas, como capim elefante, frutíferas e hortas, contrastando com áreas de agricultura em pousio e de pastagens que permanecem secas nesse período.

De acordo com os valores médios de NDVI apresentados na figura 10, observa-se que os maiores valores de NDVI foram verificados, em ambos os períodos, nos municípios de Matureia, Salgadinho, Areia de Baraúnas e Teixeira. Nessas áreas a geomorfologia é expressa por morros e serras com altitudes, que variam de 600 a $1185 \mathrm{~m}$ de altitude, conforme verificado no Pico do Jabre, ponto culminante do estado da Paraíba.

Essas áreas são marcadas pela presença de uma flora e fisionomia bem distintas da formação vegetacional da caatinga. Em sua maioria, essas áreas são compostas por uma vegetação densa, com baixa frequência de indivíduos herbáceos e cactáceas, sendo mais frequente a presença de arbustos e árvores insertos na tipologia "caatinga arbustiva arbórea fechada". Além de formação de vegetal de caatinga, também foi verificado a ocorrência de espécies de outras formações florestais, conforme verificado por Cunha et al. (2013), no estudo da flora lenhosa da Floresta Estacional Semidecídual Montana do Pico do Jabre-PB

Além da topografia do terreno, devem-se incluir ademais, o domínio favorável de fatores edafoclimáticos à sustentação desta diversidade vegetacional, influenciando diretamente nos valores de NDVI. Segundo Da Silva Barbosa et al. (2017), em áreas de relevo plano, com altitude superior a 600 metros, há ocorrência de solos mais desenvolvidos e profundos, com boa capacidade de armazenamento de água. De acordo com os mesmos autores, a ocorrência de nascentes perenes nesses lugares também influencia na manutenção ecológica de ambientes mais úmidos, contribuindo de forma direta na manutenção e conservação das folhagens das plantas.

Evidencia-se que, além da influência topográfica, é possível que a distribuição irregular das chuvas na região tenha ocasionado alterações significativas nos valores de NDVI. Nesses municípios, verificou-se a ocorrência de chuvas no ano de 2005, até o $2^{\circ}$ decêndio de agosto, enquanto no ano de 2015 o período chuvoso, atipicamente se estendeu até final de julho. Esses resultados sugerem que as modificações nos valores de NDVI podem ser mais expressivas em função da temporalidade da umidade retida no solo do que propriamente da precipitação.

De acordo com Nicácio et al. (2009), há uma defasagem temporal entre a precipitação e a resposta espectral da vegetação, devido ao tempo necessário para o acúmulo de água no solo e absorção pela planta, possibilitando um melhor vigor vegetativo. A variabilidade pluviométrica e as condições limitantes do solo refletem nas características fisionômicas da vegetação, interferindo de maneira significativa na regularização da atividade fotossintética e transpirativa, notadas através da variabilidade nos valores do NDVI. Essa defasagem temporal entre precipitação e acúmulo de biomassa verde é fundamental para a recuperação da capacidade fotossintética e na produção de carboidratos estruturais designados à formação das folhas (BARBOSA et al., 2011).

Em relação a variação interanual dos valores médios de NDVI, observa-se que as maiores reduções foram observadas nos municípios de Matureia, Santa Teresinha e Salgadinho. Estes decréscimos foram provocados pela expansão de atividades antrópicas nessas áreas, assim como pelos baixos índices pluviométricos registrados nos municípios de Matureia e Santa Teresinha ano de 2015, com reduções de $514 \mathrm{~mm}$ e $408 \mathrm{~mm}$, respectivamente.

Com base na correlação existente entre os valores médios de NDVI e os dados de precipitação acumulada. De modo geral, as correlações mais baixas foram verificadas nos períodos chuvosos, com menor valor no ano de 2005.

O ano de 2005 foi marcado pela alta variabilidade pluviométrica na região, com totais pluviométricos que variam de 303,1 $\mathrm{mm}$ a $793 \mathrm{~mm}$ nos municípios de Areia de Baraúnas e Santa Teresinha, respectivamente. Tais resultados foram influenciados principalmente pelos valores encontrados nos municípios de Areia de Baraúnas e Salgadinho, apresentando as maiores amplitudes entre os totais pluviométricos e as leituras de NDVI para a região.

Em suma, pode-se dizer que os valores de NDVI, para essas regiões, estão relacionados a outros fatores como relevo, solo e tipo de vegetação presentes nessas áreas do que propriamente na quantidade de chuvas registradas nesses períodos. Estas estações contribuíram de forma significativa para os resultados obtidos, com uma correlação calculada para esse período de aproximadamente $81 \%$.

$\mathrm{O}$ ano de 2015 registrou menores índices pluviométricos (378 mm), em relação a $2005(520 \mathrm{~mm})$, no entanto as precipitações pluviométricas em 2015 expressaram uma 
melhor distribuição espacial na região, com os menores índices registrados em Areia de Baraúnas $(245 \mathrm{~mm})$ e os maiores valores em Serra Negra $(568 \mathrm{~mm})$. A correlação entre a chuva e o NDVI, para esse período, foi influenciada negativamente pelo município de Patos, que, apesar de apresentar um regime pluviométrico acima da média para a região $(468 \mathrm{~mm})$, obteve também um valor abaixo da média para o NDVI, apenas 0,24. Esta plataforma sozinha colaborou para a redução do resultado apresentado no gráfico de dispersão, com redução de $51,2 \%$ no valor de $\mathrm{R}$ para esse período.

A região onde se encontra a estação pluviométrica de Patos é uma área bastante antropizada, marcada pela presença de uma vegetação do tipo Caatinga Arbustiva Arbórea Aberta, com predominância de ervas, arvoretas e árvores esparsas. As espécies arbóreas encontradas na área são Mimosa tenuiflora (Willd) (jurema preta), Combretum leprosum Mart (mufumbo), Croton sonderianus Muell. Arg. (marmeleiro), Poincianella pyramidalis (catingueira) e Aspidosperma pyrifolium Mart (pereiro). Portanto, a baixa correlação verificada nesse período pode estar associada à predominância de espécies com baixa resposta espectral, devido principalmente às características anatômicas de suas folhas, que são, em geral, pequenas, compostas, alternas e bipinadas.

De acordo com Russel (2001), a estrutura geométrica dos dosséis das florestas contribui de forma significativa nos padrões de resposta espectral da cobertura vegetal de uma imagem. No estudo realizado por Yanagi (2006), foram constatadas mudanças nos valores de refletância, nas bandas do visível e do infravermelho próximo, em função das modificações arquitetônicas da vegetação (disposição das folhas) e parâmetros ópticos (refletividade das folhas).

Os resultados demostraram que o aumento dos níveis pluviométricos na região não implicou o aumento progressivo nos valores de NDVI. Observa-se que, até determinado nível de precipitação a correlação se mantém normal, no entanto, ao se atingir em níveis elevados de precipitação, ocorre redução da atividade fotossintética (DE OLIVEIRA GOULART et al., 2015). Resultados semelhantes foram encontrados por Wang et al. (2003), que examinaram as respostas temporais do NDVI à precipitação e temperatura Central das Grandes Planícies, EUA, em Kansas, e concluíram que a relação entre precipitação e NDVI é forte e previsível quando visualizada na escala espacial apropriada.

As maiores correlações foram verificadas nos períodos seco dos anos de 2005 e 2015, respectivamente. Esses resultados são reflexos da precipitação acumulada nos três meses anteriores a passagem dos satélites, permeando a resposta espectral nas áreas de vegetação nativa.

Diversos estudos têm demonstrado a influência da precipitação antes da passagem do satélite no comportamento espectral da vegetação caatinga. Silva et al. (2019) observaram que a umidade do solo acumulada nos 3 meses que antecederam a passagem do satélite contribuiu na elevação dos valores de NDVI, através da manutenção dos extratos herbáceos e presença marcante do dossel foliar da vegetação. De acordo com Nicácio et al. (2009) a resposta da vegetação à redução pluviométrica ocorre com uma defasagem de aproximadamente quatro meses. Barbosa et al. (2011), constataram uma relação de dependência entre NDVI e precipitação, com maiores correlações verificadas na ocorrência de chuvas com defasagem temporal de 2 a 3 meses. Arraes et al. (2012) destacam que o aumento do
NDVI está relacionado com a umidade do solo dos meses anteriores.

Essa defasagem ocorre, principalmente, pela interação entre solo e planta, considerando o solo como o principal fornecedor de água e nutrientes para as plantas. Cada tipo de solo possui sua capacidade de água disponível, ou seja, mesmo após a drenagem da água, ocorre a sua permanência nas partículas do solo, estando disponível para ser utilizada pelo vegetal. Além disso, as áreas com solos profundos permitem que a vegetação natural apresente adaptações fisiológicas, em virtude das condições edafoclimáticas, com raízes profundas, troncos corticosos e folhas coriáceas, que são capazes de aproveitar a água presente nas superfícies mais profundas do solo e também impedir as perdas da mesma (NICÁCIO et al., 2009).

\section{CONCLUSÕES}

A variação espaço temporal do NDVI mostrou-se uma ferramenta satisfatória para a identificação das alterações da cobertura vegetal verificada na sub-bacia do Rio Espinharas, entre os anos analisados.

Os maiores valores de NDVI foram encontrados nas estações dos municípios de Maturéia, Salgadinho, Areia de Baraúnas e Teixeira, para ambos os anos analisados, demonstrando a influência da altitude e declividade do terreno nos valores desse índice.

As maiores correlações para as variáveis analisadas foram verificadas nos períodos secos, indicando uma relação progressiva entre as variáveis, com a diminuição dos totais pluviométricos.

A elevação dos níveis pluviométricos na região não implicou o aumento progressivo nos valores de NDVI, indicando que o aumento da atividade fotossintética se dá até determinado nível de precipitação, no entanto, ao se atingirem níveis elevados de precipitação, ocorre redução do desenvolvimento foliar. Isso explica as baixas correlações apresentadas nos períodos úmidos.

Sugere-se, para futuros estudos na região, que seja analisado um período maior de observação, objetivando mitigar o efeito de situações extremas. Além da precipitação acumulada, outros fatores podem ser correlacionados, como declividade do terreno, temperatura e tipo de solo por sua expressividade na interação sinérgica do meio físico, destarte, sugerindo-se sua análise integrada.

\section{AGRADECIMENTOS}

Agradecemos ao Programa de Pós-Graduação em Ciências Florestais e à CAPES pela cessão da bolsa de estudos.

\section{REFERÊNCIAS}

AESA_Agência Executiva de Gestão das Águas do Estado da Paraíba. Mapa interativo. AESA, 2010. Disponível em:<http://www.aesa.pb.gov.br/geoprocessamento/ge oportal/sigaesaweb.html>. Acesso em: 11. jan. 2017.

AQUINO, C. M. S.; OLIVEIRA, J. G. B. Estudo da dinâmica do Índice de Vegetacão por Diferença Normalizada (NDVI) no Núcleo de São Raimundo Nonato-PI. GEOUSP - Espaço e Tempo, São Paulo, n. 31, p. 157-168, 2012. DOI: https://doi.org/10.11606/issn.21790892.geousp.2012.7 4261

ARRAES, F. D. D.; ANDRADE, E. M.; SILVA, B. B. Dinâmica do balanço de energia sobre o açude Orós e 
suas adjacências. Revista Caatinga, Mossoró, v. 25, n. 1, p. 119-127, 2012.

ARAÚJO, I. P.; LIMA, J. R.; MENDONÇA, I. F. C. Uso e degradação dos recursos naturais no semiárido brasileiro: estudo na Microbacia Hidrográfica do Rio Farinha, Paraíba, Brasil. Caminhos de Geografia, Uberlândia, v. 12, n. 39, p. 255-270, 2011.

BARBOSA, H. A.; KUMAR, T. V. L.; SILVA JUNIOR, I. W. Analysis of the NDVI Temporal Dynamics in Semiarid Ecosystems: Brazilian Caatinga and African Western Sahel. Revista Brasileira de Geografia Física, Recife, v. 2, p. 300-306, 2011. DOI: 10.26848/rbgf.v4i2.232655

DE OLIVEIRA GOULART, A. C.; DELGADO, R. C.; DE OLIVEIRA JÚNIOR, J. F.; DE GOIS, G.; DOS SANTOS, E. O. Relação espectro-temporal entre índices de vegetação e a chuva na cidade do Rio de Janeiro. Revista de Ciências Agrárias, Belém, v. 58, n. 3, p. 277-283, 2015. DOI: http://doi.editoracubo.com.br/10.4322/rca.1990

BEZERRA, J. M.; MOURA, G. B.; SILVA, B. B.; LOPES, P. M.; SILVA, Ê. F. F. Parâmetros biofísicos obtidos por sensoriamento remoto em região semiárida do estado do Rio Grande do Norte, Brasil. Revista Brasileira de Engenharia Agrícola e Ambiental, Campina Grande, v. 18, n. 1, p. 73-84, 2014. DOI: https://dx.doi.org/10.1590/s1415-43662014000100010

CUNHA, J. E. D. B. L.; RUFINO, I. A. A.; SILVA. B. B.; CHAVES, I. D. B. Dinâmica da cobertura vegetal para a Bacia de São João do Rio do Peixe, PB, utilizando-se sensoriamento remoto. Revista Brasileira de Engenharia Agrícola e Ambiental, Campina Grande, v. 16, n. 5, p. 539-549, 2012. DOI: https://doi.org/10.1590/S1415-43662012000500010

CUNHA, M.; DA SILVA JÚNIOR, M. C.; DE LIMA, R. B. A flora lenhosa na Floresta Estacional Semidecídua Montana do Pico do Jabre, PB. Revista Brasileira de Ciências Agrárias, Recife, v. 8, n. 1, p. 130-136, 2013. DOI: 10.5039 /agraria.v8i1a2294

DA SILVA BARBOSA, A. H.; DE CARVALHO, R. G.; CAMACHO, R. G. V. Aplicação do NDVI para a análise da distribuição espacial da cobertura vegetal na Região Serrana de Martins e Portalegre-Estado do Rio Grande do Norte. Revista do Departamento de Geografia, São Paulo, v. 33, p. 128-143, 2017. DOI: https://doi.org/10.11606/rdg.v33i0.128171

FERREIRA, S. M. J.; FERREIRA, F. S. H.; SILVA, A. H.; SANTOS, M. A.; GALVÍNCIO, D. J. Análise EspaçoTemporal da Dinâmica da Vegetação de Caatinga no Município de Petrolina-PE. Revista Brasileira de Geografia Física, Recife, v. 4, p. 904-922, 2012. DOI: https://doi.org/10.26848/rbgf.v5.4.p904-922

FOODY, G. M. Assessing the accuracy of land cover change with imperfect ground reference data. Remote Sensing of Environment, v. 114, p. 2271-2285, 2010. DOI: https://doi.org/10.1016/j.rse.2010.05.003

FRANCISCO, P. R. M.; CHAVES, I. B.; LIMA, E. R. V. Mapeamento das Terras para Mecanização Agrícola Estado da Paraíba. Revista Brasileira de Geografia Física, Recife, v. 5, n. 2, p. 233-249, 2012. DOI: 10.26848/rbgf.v5i2.232784

IBGE_Instituto Brasileiro de Geografia e Estatística. Censo, $2010 . \quad$ Disponível em: <http://www.ibge.gov.br/cidadesat/topwindow.htm?1 $>$. Acesso em 11/02/2017.
LIMA, A. L. A.; RODAL, M. J. N. Phenology and wood density of plants growing in the semi-arid region of northeastern Brazil. Journal of Arid Environments, v. 74, n. 11, p. 1363-1373, 2010. DOI: https://doi.org/10.1016/j.jaridenv.2010.05.009

LOPES, H. L.; CANDEIAS, A. L.; ACCIOLY, L. J.; SOBRAL, M. D.; PACHECO, A. P. Parâmetros biofísicos na detecção de mudanças na cobertura e uso do solo em bacias hidrográficas. Revista Brasileira de Engenharia Agrícola e Ambiental, Campina Grande, v. 14, n. 11 , p. 1210-1219, 2010. DOI: https://doi.org/10.1590/S1415-43662010001100011

MARKHAM, B. L.; BARKER, L. L. Thematic mapper bandpass solar exoatmospherical irradiances. International Journal of Remote Sensing, v. 8, n. 3, p. 517-523, $1987 . \quad$ DOI: https://doi.org/10.1080/01431168708948658

NASSUR, O. A. C.; FERREIRA, E.; SÁFADI, T.; DANTAS, A. A. A. Monitoramento e projeção futura da vegetação no Parque Nacional do Itatiaia através de sensoriamento remoto. Cerne, Lavras, v. 21, n. 3, p. 511 517, 2015. DOI: 10.1590/01047760201521031823

NICÁCIO, R. M.; ARAUJO, L. L.; GONZAGA, E. P.; LIBOS, M. I. P. de C.; OLIVEIRA, L. M. T. de. Relação NDVI e Precipitação na Bacia do Rio Coxim - MS. Geografia, Rio Claro, v. 43, p. 667-680, 2009.

PONZONI, F. J.; SHIMABUKURO, Y. E. A imagem como fonte de dados radiométricos (abordagem quantitativa). PONZONI, FJ, SHIMABUKURO, YE Sensoriamento remoto no estudo da vegetação. São José dos Campos: Parêntese, 2010. p. 68-102.

RUSSELL, M. Monitoring regional vegetation change using reflectance measurements from multiple solar zenith angles. Environment international, v. 27, n. 2-3, p. 211217, 2001. DOI: https://doi.org/10.1016/S01604120(01)00089-7

SILVA, D. A. O.; LOPES, P. M. O.; MOURA, G. B. D. A.; SILVA, E. F. D. F.; SILVA, J. L. B. D.; BEZERRA, A. C. Evolução Espaço-Temporal do Risco de Degradação da Cobertura Vegetal de Petrolina-PE. Revista Brasileira de Meteorologia, v. 34, n. 1, p. 89-99, 2019. DOI:http://dx.doi.org/10.1590/0102-7786334018

SILVA, R. M. P. S.; LIMA, J. R.; MENDONÇA, I. F. C. Alteração da cobertura vegetal na sub-bacia do Rio Espinharas no período 2000 - 2010. Revista Brasileira de Engenharia Agrícola e Ambiental, Campina Grande, v. 18, n.2, p. 202-209, 2014. DOI: https://doi.org/10.1590/S1415-43662014000200011

SOBRINHO, T. A.; OLIVEIRA, P. T. S.; RODRIGUES, D. B. B.; AYRES, F. M. Delimitação automática de bacias hidrográficas utilizando dados SRTM. Engenharia Agrícola, Jaboticabal, v. 30, n. 1, p. 46-57, 2010.DOI: https://doi.org/10.1590/S0100-69162010000100005.

WANG, J.; RICH, P. M.; PRICE, K. P. Temporal responses of NDVI to precipitation and temperature in the central Great Plains, USA. International journal of remote sensing, v. 24 , n. 11, p. 2345-2364, 2003. DOI: https://doi.org/10.1080/01431160210154812

YANAGI, S. N. M. Modeling Radiative Transfer in Tropical Raing Forest Canopies: Sensitivity of Simulated Albedo to Canopy Architectural Parameters. Anais da Academia Brasileira de Ciências, Rio de Janeiro, v. 83, n. 4 , p. 1231-1242, 2011. DOI: https://doi.org/10.1590/S0001-37652011000400010 